\title{
Association between visceral adiposity and DDX11 as a predictor of aggressiveness of small clear-cell renal-cell carcinoma: a prospective clinical trial
}

Jee Soo Park, Won Sik Jang, Jongchan Kim, Seung Hwan Lee, Koon Ho Rha and Won Sik Hamº

\begin{abstract}
Background: Visceral fat produces several hormones and cytokines associated with carcinogenesis and tumor progression. Herein, we investigated the association between visceral adiposity and target-gene mRNA expression in patients with localized small clear-cell renal-cell carcinoma (ccRCC).

Methods: We included 200 patients with localized clinical T1a stage ccRCC who had undergone nephrectomy from November 2018 to November 2020 in a prospective clinical trial (NCT03694912). Visceral, subcutaneous, and total adipose tissue in these patients was measured via preoperative computerized tomography of the mid-third lumbar vertebra region. We then examined the association between adiposity and the mRNA levels of PBRM1, BAP1, SETD2, KDM5C, FOXC2, CLIP4, AQP1, DDX11, BAIAP2L1, and TMEM38B in matched frozen tumor tissues and plasma samples.

Results: Upon the stratification of patients into quartiles according to their relative visceral adiposity, high visceral adiposity was found to be significantly associated with low ISUP grade $(P=0.004)$. Multivariate logistic regression analysis revealed a significant association between frozen tissue DDX11 expression and high visceral adiposity (OR $0.676,95 \% \mathrm{Cl} 0.587-0.779, P<0.001)$. Moreover, frozen tissue DDX11 expression was significantly associated with high ISUP grade (OR 1.556, 95\% Cl 1.223-1.981, $P<0.001$ ). The frozen tissue mRNA expression of DDX11 was identified as a biomarker for visceral adiposity and cancer aggressiveness.

Conclusions: The results obtained herein will aid in inferring the aggressiveness of small ccRCCs, represented by ISUP nuclear grade, in clinical practice. Our findings indicated that DDX11 and visceral fat play active roles in small ccRCC. These roles should be examined in future studies for the possible use of DDX11 and visceral fat as prognostic biomarkers in the treatment of patients with cCRCC.
\end{abstract}

Trial registration: ClinicalTrials.gov, NCT03694912, Registered 3 October 2018.

Keywords: Adipose tissue, Clear-cell renal-cell carcinoma, Intra-abdominal fat, Obesity, Small renal mass

\section{Background}

Renal-cell carcinoma (RCC) is the sixth and tenth most common type of cancer in men and women worldwide, respectively [1]. Clear-cell RCC (ccRCC) represents the

\footnotetext{
* Correspondence: uroham@yuhs.ac

Department of Urology and Urological Science Institute, Yonsei University College of Medicine, Seoul, Republic of Korea
}

most prevalent type of RCC, and it is characterized by mutations in genes governing the hypoxia signaling pathway. Several studies have identified specific genetic variances, and possible biomarkers for ccRCC, leading to therapeutic innovations [2]. However, the tumor biology of most commonly identified masses, which are $\leq 4 \mathrm{~cm}$ in diameter and classified as small renal masses (SRMs),

(c) The Author(s). 2021 Open Access This article is licensed under a Creative Commons Attribution 4.0 International License, which permits use, sharing, adaptation, distribution and reproduction in any medium or format, as long as you give appropriate credit to the original author(s) and the source, provide a link to the Creative Commons licence, and indicate if changes were made. The images or other third party material in this article are included in the article's Creative Commons licence, unless indicated otherwise in a credit line to the material. If material is not included in the article's Creative Commons licence and your intended use is not permitted by statutory regulation or exceeds the permitted use, you will need to obtain permission directly from the copyright holder. To view a copy of this licence, visit http://creativecommons.org/licenses/by/4.0/ The Creative Commons Public Domain Dedication waiver (http://creativecommons.org/publicdomain/zero/1.0/) applies to the data made available in this article, unless otherwise stated in a credit line to the data. 
is poorly understood $[3,4]$. A wide variety of therapeutic modalities is used against SRMs, including surgical tumor resection, ablation, as well as active surveillance in some instances. Therefore, understanding the molecular characteristics and pathogenesis of SRMs is important for identifying specific biomarkers and selecting the optimal therapeutic options in clinical settings [4].

Although obesity represents a well-established risk factor regarding RCC $[5,6]$, the detailed association between obesity and the prognosis of RCC patients is still controversial and unclear. Some studies have reported improved prognoses in overweight patients [6-12], whereas other studies have reported no association between the clinical course of RCC and body weight [13, 14]. Regarding SRMs, the prognosis of RCC is inversely proportional to the body mass index (BMI), indicating that the tumor biology of SRMs is distinct from that of non-SRMs.

Previous studies have mostly employed BMI as a measure of obesity; however, BMI cannot be used to distinguish between fat, muscle, and bone. Furthermore, BMI does not provide any information on fat distribution. The measurement of visceral fat can be used to assess true obesity because visceral fat is the largest endocrine organ in the body, producing several hormones and cytokines related to carcinogenesis and tumor progression [15].

Previously, we found that several potential prognostic biomarkers are considerably up- or downregulated in ccRCC, and can be used to identify the aggressive clinical T1-stage [16, 17]. Total RNA sequencing data of 24 ccRCC patients (12 patients each with and without aggressive characteristics) revealed 10 genes highly upregulated or downregulated associated with aggressive disease. Among these 10 genes, DDX11 was significantly upregulated in aggressive ccRCC and was associated with low cancer-specific survival and high recurrence rate [17]. In this study, we aimed to determine the association between visceral adiposity and the mRNA expression of potential biomarkers using frozen tumor tissues and preoperative plasma of patients with small ccRCC. The present study presents information regarding the development of rapid and straightforward techniques for the evaluation of the aggressiveness of small ccRCCs in clinical practice.

\section{Materials and methods}

\section{Patients and tissues}

All procedures involving human participants were performed in accordance with the ethical standards of the institutional and/or national research committee as well as the 1964 Helsinki Declaration and its later amendments or comparable ethical standards. The study was approved by the Institutional Review Board of the
Yonsei University Health System (project no: 4-20180753). Written informed consent was obtained from all patients, and the manuscript does not contain any person's data in any form.

The present study included 200 patients with small localized ccRCC $(\leq 4 \mathrm{~cm}, \mathrm{pT} 1 \mathrm{aNOM0})$, who were treated via nephrectomy only, and for whom frozen tumor tissues and matching preoperative plasma samples were available from a prospective study (ClinicalTrials.gov Identifier: NCT03694912) conducted between November 2018 and November 2020.

The inclusion criteria used were as follows: (1) localized small ccRCC ( $\leq 4 \mathrm{~cm}$, pT1aNOM0); (2) availability of information on preoperative height and weight; (3) availability of preoperative computed tomography $(\mathrm{CT})$ data and follow-up for more than 1 year; and (4) no neoadjuvant or adjuvant systemic therapy. Clinicopathological data, including age, sex, BMI, and tumor size, were recorded for each patient. All tumors were reviewed according to the 2016 World Health Organization (WHO) classification [18] and International Society of Urologic Pathologists (ISUP) grading [19]. Grades 1 and 2 were considered as low-grade disease, while grades 3 and 4 were considered as high-grade disease. Minimum four slides were reviewed for each case in order to minimize bias from intratumoral heterogeneity (ITH). Tumor grade was blindly reviewed by three independent pathologists, in order to minimize the inter-pathologist reliability. For a consensus diagnosis, at least 2 of the 3 pathologist' diagnoses had to agree. Diameters of the primary tumors were obtained via $\mathrm{CT}$ imaging. Collected tumor tissues and plasma samples were stored in liquid nitrogen and $-80^{\circ} \mathrm{C}$ until total RNA extraction. All PCR samples were analyzed at the same time. We assessed the expression levels of six genes (PBRM1, BAP1, SETD2, KDM5C, FOXC2, and CLIP4) reportedly associated with ccRCC, and four genes (AQP1, DDX11, BAIAP2L1, and TMEM38B) examined in our previous study involving RNA-seq analysis of aggressive ccRCC in clinical T1 stage [16, 17].

\section{Adiposity measurement}

As shown in Fig. 1, the contents of visceral adipose tissue (VAT), subcutaneous adipose tissue, and total adipose tissue were measured via preoperative CT of the mid-third lumbar vertebra region using Aquarius iNtuition Viewer, version 4.4.12 (TeraRecon, Foster City, CA, USA) with patients in a supine position. Preoperative CT was performed within 1 month before the surgery in order to minimize the change in body fat tissue over time. Previous studies have consistently used mid-third lumbar level for CT-defined image analysis [20]. Different body compositions were evaluated using predefined Hounsfield unit (HU) thresholds: - 190 to - $30 \mathrm{HU}$ for subcutaneous adipose tissue, and -150 to $-50 \mathrm{HU}$ for 


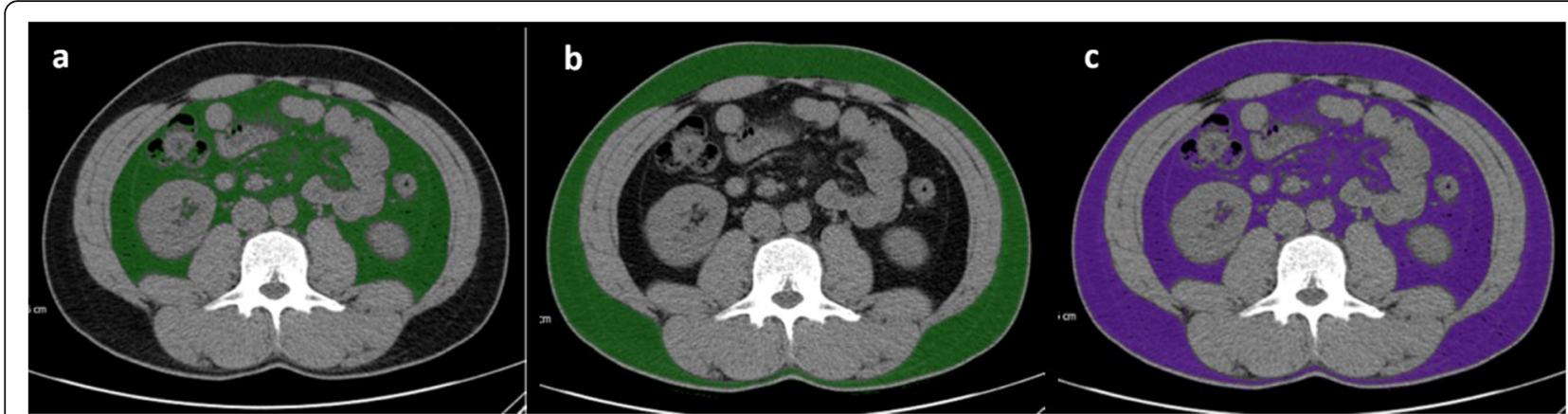

Fig. 1 Computed tomography (CT) analysis of visceral and subcutaneous adipose tissue. Measurement of a visceral adipose tissue (VAT), b subcutaneous adipose tissue (SAT), and c total adipose tissue (TAT) by CT analysis software for a representative patient

VAT [20]. VAT\% was calculated using the formula $\mathrm{VAT} \%=[\mathrm{VAT} /$ total adipose tissue $] \times 100[20]$.

\section{Blood sample processing}

Peripheral blood was collected from each participant, aliquoted into ethylenediaminetetraacetic acid (EDTA)coated tubes, and centrifuged at $1600 \times g$ for $10 \mathrm{~min}$ at 4 ${ }^{\circ} \mathrm{C}$. The plasma was then carefully transferred into new tubes and further centrifuged at $4000 \times g$ for $10 \mathrm{~min}$ at 4 ${ }^{\circ} \mathrm{C}$ and stored at $-80{ }^{\circ} \mathrm{C}$ until further analysis.

\section{RNA extraction and reverse transcription-quantitative polymerase chain reaction (RT-qPCR)}

Total RNA was extracted from frozen tissues and plasma samples using TRIzol (Ambion, Life Technologies, USA). RNA isolated from $1 \mathrm{~mL}$ of plasma was dissolved in $20 \mu \mathrm{L}$ of DEPC-treated water. The quantity and quality of RNA were assessed using a Nanodrop spectrophotometer (NanoDrop ND-1000, Thermo Scientific, Wilmington, DE, USA). Precisely $1 \mu \mathrm{g}$ per sample was reverse-transcribed into first-strand cDNA using an iNtRon Maxime RT PreMix (Cat No. 25082; Intronbi, Seongnam, South Korea), following the manufacturer's protocol. qPCR was performed using Power SYBR ${ }^{\odot}$ Green Master Mix (Thermo Fisher, Cat No. A25742, USA) in a $10-\mu \mathrm{L}$ reaction volume consisting of $5 \mu \mathrm{L}$ of SYBR Green master PCR mix, $1 \mu \mathrm{L}$ each of the forward and reverse primers $(10 \mathrm{pmol}), 1 \mu \mathrm{L}$ of the diluted cDNA template, and UltraPure ${ }^{\mathrm{TM}}$ distilled water (Invitrogen, NY, USA). The conditions for amplification are listed as follows: initial denaturation at $95^{\circ} \mathrm{C}$ for $10 \mathrm{~min}$; 40 cycles of denaturation at $95{ }^{\circ} \mathrm{C}$ for $15 \mathrm{~s}$, annealing at $58{ }^{\circ} \mathrm{C}$ for $60 \mathrm{~s}$, and elongation at $72{ }^{\circ} \mathrm{C}$ for $60 \mathrm{~s}$; and final elongation at $72{ }^{\circ} \mathrm{C}$ for $5 \mathrm{~min}$. qPCR was performed on an ABI StepOnePlus Real-Time PCR System (Applied Biosystems, Foster City, CA, USA). All measurements were conducted using GAPDH as the reference gene to normalize the relative expression levels of the target genes. PCR primer sequences are shown in Table S1.
The relative gene expression was analyzed using the $2^{-\Delta \Delta C T}$ method, and the results are expressed as percentage change compared to the control values. At least three replicates of RT-qPCR experiments were performed, and the results were analyzed by a blinded investigator.

\section{Statistical analyses}

Data are presented as the means \pm standard deviations or median (interquartile ranges) for continuous variables, and as percentage for categorical variables. Locally weighted scatterplot smoothing curves and Pearson's correlation coefficient were used to assess the relationship between BMI and total adipose tissue, subcutaneous adipose tissue, VAT, or VAT\%. High visceral adiposity was defined as a VAT level higher than the median VAT level. For univariate analysis, Wilcoxon test, Student's $t$ test, or one-way analysis of variance was used to compare continuous variables, and chi-square test or Fisher's exact test was used to compare categorical variables. Multivariate logistic regression analyses were performed to identify predictors of high visceral adiposity and high ISUP grade, and odds ratios (ORs) with 95\% confidence intervals (CIs) were calculated. SPSS software version 23.0 (IBM Corp., Armonk, NY, USA) was used for all statistical analyses. All statistical tests were two-tailed. $P$ values less than 0.05 were considered statistically significant.

\section{Results}

\section{Baseline demographics}

The clinicopathological features of the study population (200 patients) are listed in Table 1. The median patient age was 52.0 years, and $76.5 \%$ of the patients were men. The median BMI was $24.8 \mathrm{~kg} / \mathrm{m}^{2}$, and one $(0.5 \%)$ patient was classified as underweight (less than $18.5 \mathrm{~kg} / \mathrm{m}^{2}$ ), 101 $(50.5 \%)$ as normal weight (18.5 to $\left.24.9 \mathrm{~kg} / \mathrm{m}^{2}\right), 85$ (42.5\%) as overweight (25 to $29.9 \mathrm{~kg} / \mathrm{m}^{2}$ ), and $13(6.5 \%)$ as obese $\left(30 \mathrm{~kg} / \mathrm{m}^{2}\right.$ or greater) according to the WHO 
BMI cutoff points [21]. The median tumor size was 2.0 $\mathrm{cm}$, and $84(42.0 \%)$ tumors were classified as high-grade.

The prevalence of hypertension, diabetes, and hypercholesterolemia in the patient population was $36.0 \%, 10.0 \%$, and $8.0 \%$, respectively (Table 1 ). As shown in Fig. 2, the total adipose tissue content [Pearson's correlation coefficient $(r)=0.505, P<0.001)$ ] and the subcutaneous adipose tissue content $(r=0.536, P<0.001)$ were significantly correlated with BMI. The VAT content $(r=0.274, P<0.001)$ demonstrated significant correlations with BMI, however, VAT\% $(P=0.207)$ did not. Age, hypertension, diabetes status, hypercholesterolemia, smoking status, and alcohol consumption differed significantly between men and women enrolled in the study (Table 1). Apart from subcutaneous adipose tissue, the adiposity variables, BMI, total adipose tissue, VAT, and VAT\% were all significantly higher in men than in women.

\section{Clinicopathological characteristics according to VAT}

Patients were stratified into quartiles (Q1 to Q4) according to the relative VAT contents (Table 2). High VAT content at diagnosis was associated with the male sex, an increased BMI, an increased prevalence of hypercholesterolemia, current smoking and alcohol status, as well as a low ISUP grade. Although significant differences were found among different VAT quartiles in terms of age, tumor size, prevalence of hypertension, they did not show any tendency.

\section{Expression of target genes in frozen tissues and plasma according to high visceral adiposity}

The relative mRNA levels of $D D X 11$ in the frozen tissue and plasma were significantly lower in patients with high visceral adiposity, revealed using univariate analysis $(P<$ 0.001 and $P=0.016$, respectively) (Table 3 ). Multivariate logistic regression analysis of 10 target gene expressions from frozen tissue and plasma reported the significant association in frozen tissue $D D X 11$ expression according to high VAT (OR 0.676, 95\% CI 0.587-0.779, $P<$ 0.001 ) (Table 3). FOXC2 and $A Q P 1$ expression in frozen tissue were also significantly associated with high VAT in multivariate logistic regression analysis $(F O X C 2$, OR

Table 1 Clinicopathological characteristics of the study population according to gender

\begin{tabular}{|c|c|c|c|c|}
\hline & Total $(n=200)$ & Men $(n=153 ; 76.5 \%)$ & Women $(n=47 ; 23.5 \%)$ & $P$ \\
\hline Median age (range) & $52.0(43.0-60.8)$ & $50.0(42.0-54.0)$ & $66.0(60.0-68.0)$ & $<0.001$ \\
\hline Median tumor size (cm) (range) & $2.0(1.4-2.9)$ & $2.0(1.4-2.8)$ & $2.1(1.4-3.6)$ & 0.275 \\
\hline Median BMI (kg/m²) (range) & $24.8(23.5-27.7)$ & $26.7(24.2-28.6)$ & $23.0(21.9-24.2)$ & $<0.001$ \\
\hline Median TAT (mm²) (range) & $29,205(24,937-37,647)$ & $31,005(26,140-39,174)$ & $26,400(20,232-27,316)$ & $<0.001$ \\
\hline Median SAT (mm²) (range) & $13,268(10,127-17,695)$ & $13,422(10,127-18,016)$ & $13,268(11,218-17,042)$ & 0.609 \\
\hline Median VAT (mm²) (range) & $15,982(11,302-19,879)$ & $18,244(14,495-20,584)$ & $10,176(4626-14,048)$ & $<0.001$ \\
\hline Median VAT\% (range) & $51.4(42.9-62.5)$ & $55.0(48.5-64.4)$ & $40.7(31.8-51.4)$ & $<0.001$ \\
\hline \multicolumn{5}{|l|}{ No. comorbid conditions, n (\%) } \\
\hline Hypertension & $72(36.0 \%)$ & $46(30.1 \%)$ & $26(55.3 \%)$ & 0.002 \\
\hline Hypercholesterolemia & $16(8.0 \%)$ & $8(5.2 \%)$ & $8(17.0 \%)$ & 0.026 \\
\hline Diabetes & $20(10.0 \%)$ & $11(7.2 \%)$ & $9(19.1 \%)$ & 0.025 \\
\hline \multicolumn{5}{|l|}{ No. smoking status, $n$ (\%) } \\
\hline Never & 75 (37.5\%) & $28(18.3 \%)$ & $47(100.0 \%)$ & $<0.001$ \\
\hline Former & 70 (35.0\%) & $70(45.8 \%)$ & $0(0.0 \%)$ & \\
\hline Current & $55(27.5 \%)$ & 55 (35.9\%) & $0(0.0 \%)$ & \\
\hline \multicolumn{5}{|l|}{ No. alcohol status, n (\%) } \\
\hline Never & 69 (34.5\%) & 30 (19.6\%) & 39 (83.0\%) & $<0.001$ \\
\hline Former & $40(20.0 \%)$ & $40(26.1 \%)$ & $0(0.0 \%)$ & \\
\hline Current & 91 (45.5\%) & 83 (54.2\%) & $8(17.0 \%)$ & \\
\hline \multicolumn{5}{|l|}{ No. ISUP grade, $n(\%)$} \\
\hline Low-grade (1-2) & $116(58.0 \%)$ & $105(68.6 \%)$ & $11(23.4 \%)$ & $<0.001$ \\
\hline High-grade (3-4) & $84(42.0 \%)$ & 48 (31.4\%) & $36(76.6 \%)$ & \\
\hline
\end{tabular}

Data are presented as medians (interquartile ranges) for continuous variables and as percentage for categorical variables. $P$ values from the chi-square test or Fisher's exact test were used to calculate mean differences for categorical variables and those from Wilcoxon test were used to calculate mean differences for continuous variables. BMI body mass index, SAT subcutaneous adipose tissue, TAT total adipose tissue, VAT visceral adipose tissue, VAT\% percentage of visceral adipose tissue 

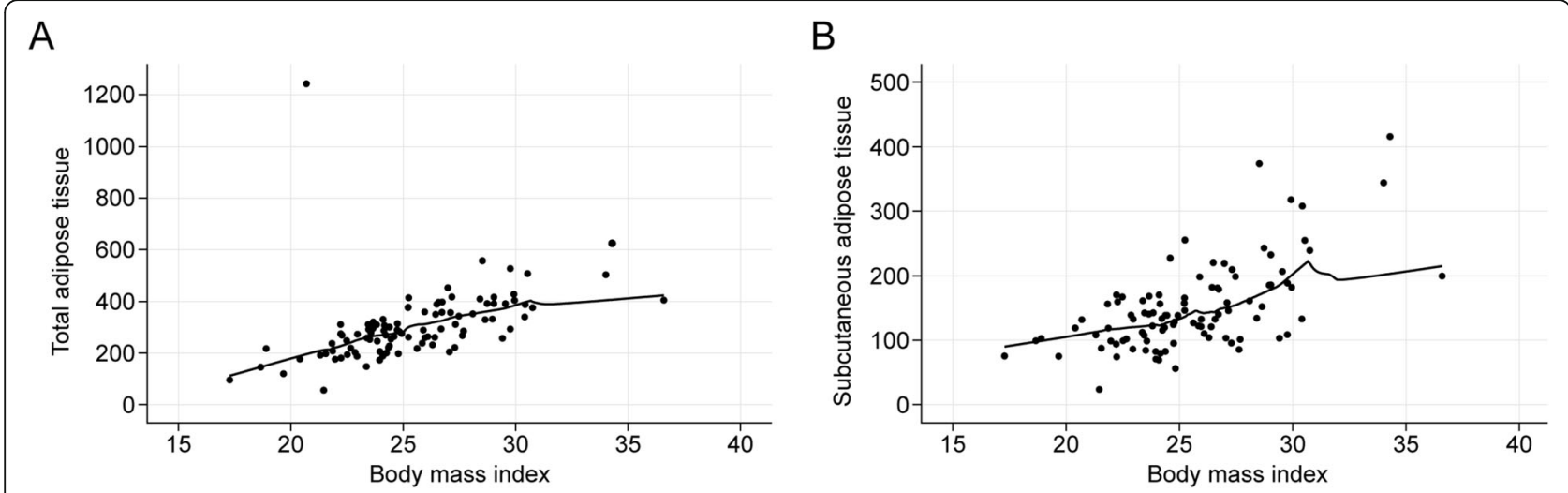

C

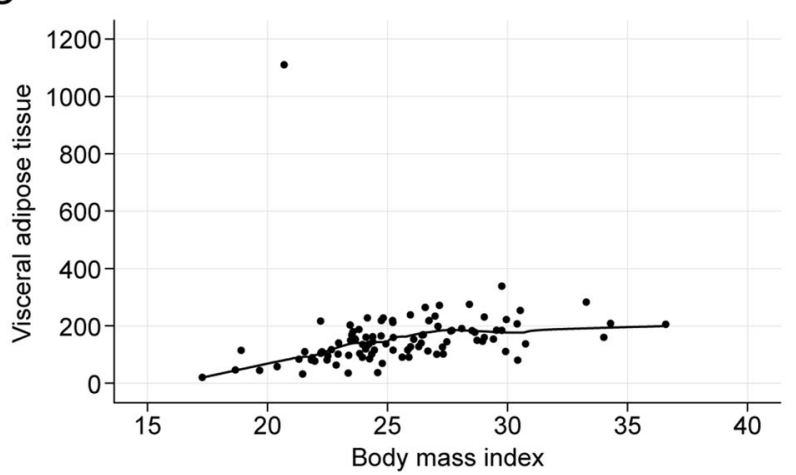

D

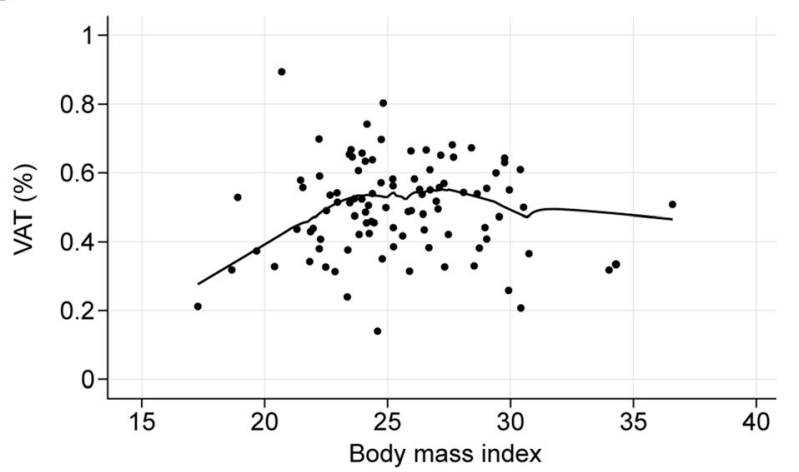

Fig. 2 Correlation between body mass index (BMI) and adipose tissue parameters. Correlation between body mass index (BMI) and a total adipose tissue (TAT), b subcutaneous adipose tissue (SAT), c visceral adipose tissue (VAT), and d VAT\%. Locally weighted scatterplot smoothing curves (blue line) were fitted in plots

0.969, 95\% CI 0.948-0.989, $P=0.003 ; A Q P 1$, OR 0.410, 95\% CI 0.212-0.793, $P=0.008$ ) (Table 3).

When we included the clinicopathological parameters and the mRNA expression of target genes that were significantly associated with VAT contents, the univariate logistic regression analysis revealed that gender, BMI, the prevalence of hypercholesterolemia, smoking and alcohol status, $D D X 11$ expression in frozen tissue, and ISUP score were significantly associated with high visceral adiposity (Table 4). Multivariate logistic regression analysis revealed that frozen tissue $D D X 11$ levels (OR 0.816, 95\% CI 0.706-0.943, $P=0.006$ ), and ISUP (OR $0.245,95 \%$ CI $0.061-0.974, P=0.046$ ) were significantly associated with high visceral adiposity (Table 4).

\section{Expression of target genes in frozen tissues and plasma according to high ISUP grade}

The relative mRNA level of $D D X 11$ in the frozen tissue was significantly higher in patients with high ISUP grade, revealed using univariate analysis $(P<0.001)$ (Table 5). Multivariate logistic regression analysis of 10 target gene expressions from frozen tissue and plasma reported the significant association in frozen tissue
DDX11 expression according to high ISUP grade (OR 1.556, 95\% CI 1.223-1.981, $P<0.001$ ) (Table 5).

\section{Expression of DDX11 in frozen tissues according to high visceral adiposity and high ISUP grade in males and females}

The separate analysis of males and females using logistic regression was performed due to the discrepancy of fat distribution between males and females. The results showed that DDX11 expression of frozen tissue for both significantly correlated with VAT $(P<0.001)$ and ISUP nuclear grade $(P<0.001)$ in males. Same results were also reported for females, showing that DDX11 expression of frozen tissue for both significantly correlated with $\operatorname{VAT}(P=0.001)$ and ISUP nuclear grade $(P=$ $0.004)$.

\section{Discussion}

In the present study, we identified the frozen tissue mRNA levels of $D D X 11$, which is involved in cellular growth and division, as an independent prognostic factor for high visceral adiposity even after adjusting for 
Table 2 Clinicopathological characteristics according to visceral adipose tissue content

\begin{tabular}{|c|c|c|c|c|c|}
\hline & Q1 & Q2 & Q3 & Q4 & $P$ \\
\hline Median age (range) & $57.5(51.0-62.0)$ & $60.0(46.0-68.0)$ & $46.0(39.0-57.3)$ & $51.0(42.0-54.0)$ & $<0.001$ \\
\hline \multicolumn{6}{|l|}{ No. gender, $n$ (\%) } \\
\hline Male & $24(48.0 \%)$ & $33(66.0 \%)$ & $46(92.0 \%)$ & $50(100.0 \%)$ & $<0.001$ \\
\hline Female & $26(52.0 \%)$ & $17(34.0 \%)$ & $4(8.0 \%)$ & $0(0.0 \%)$ & \\
\hline Median tumor size $(\mathrm{cm})$ (range) & $1.8(1.2-2.8)$ & $2.5(1.8-3.6)$ & $1.6(1.4-1.7)$ & $2.1(1.2-2.9)$ & $<0.001$ \\
\hline Median BMI (kg/m²) (range) & $22.9(21.9-24.6)$ & $24.4(23.0-26.6)$ & $27.7(24.1-29.0)$ & $27.1(25.1-29.2)$ & $<0.001$ \\
\hline \multicolumn{6}{|l|}{ No. comorbid conditions, $n$ (\%) } \\
\hline Hypertension & $13(26.0 \%)$ & $26(52.0 \%)$ & $9(18.0 \%)$ & $18(36.0 \%)$ & 0.002 \\
\hline Hypercholesterolemia & $0(0.0 \%)$ & $4(8.0 \%)$ & $4(8.0 \%)$ & $8(16.0 \%)$ & 0.034 \\
\hline Diabetes & $8(16.0 \%)$ & $3(6.0 \%)$ & $6(12.0 \%)$ & $3(6.0 \%)$ & 0.261 \\
\hline No. smoking status, $n$ (\%) & & & & & $<0.001$ \\
\hline Never & $35(70.0 \%)$ & $22(44.0 \%)$ & $12(24.0 \%)$ & $6(12.0 \%)$ & \\
\hline Former & $12(24.0 \%)$ & $22(44.0 \%)$ & $22(44.0 \%)$ & $14(28.0 \%)$ & \\
\hline Current & $3(6.0 \%)$ & $6(12.0 \%)$ & $16(32.0 \%)$ & $30(60.0 \%)$ & \\
\hline \multicolumn{6}{|l|}{ No. alcohol status, n (\%) } \\
\hline Never & $28(56.0 \%)$ & $20(40.0 \%)$ & $15(30.0 \%)$ & $6(12.0 \%)$ & $<0.001$ \\
\hline Former & $7(14.0 \%)$ & $6(12.0 \%)$ & $9(18.0 \%)$ & $18(36.0 \%)$ & \\
\hline Current & $15(30.0 \%)$ & $24(48.0 \%)$ & $26(52.0 \%)$ & $26(52.0 \%)$ & \\
\hline \multicolumn{6}{|l|}{ No. ISUP grade, $n(\%)$} \\
\hline Low-grade (1-2) & $10(20.0 \%)$ & $20(40.0 \%)$ & $46(92.0 \%)$ & $40(80.0 \%)$ & $<0.001$ \\
\hline High-grade (3-4) & $40(80.0 \%)$ & $30(60.0 \%)$ & $4(8.0 \%)$ & $10(20.0 \%)$ & \\
\hline
\end{tabular}

Data are presented as medians (interquartile ranges) for continuous variables and as percentage for categorical variables. $P$ values from one-way analysis of variance and chi-square test or Fisher's exact test were used to determine mean differences for continuous and categorical variables, respectively, based on VAT quartiles. BMI body mass index, SAT subcutaneous adipose tissue, TAT total adipose tissue, VAT visceral adipose tissue, VAT\% percentage of visceral adipose tissue

clinicopathological parameters that are significantly associated with adiposity. To the best of our knowledge, this is the first study to investigate the association between the expression of genes potentially involved in ccRCC and adiposity, as well as to use visceral adiposity as a marker to infer the aggressiveness of small ccRCC.

BMI increases the relative risk for RCC [22]. However, the association between $\mathrm{BMI}$ and $\mathrm{RCC}$ prognosis remains controversial. Prior studies have mainly reported the proportional associations between BMI and RCC prognosis, whereas inverse, flat, or null associations have also been reported [23]. The inconsistencies among the results reported by these studies may be attributed to the use of BMI as a surrogate marker for obesity. Among various types of adipose tissue, VAT is the largest endocrine organ and produces hormones and cytokines that are related to carcinogenesis and tumor progression [15]. Subcutaneous adipose tissue and VAT share scant functional similarities other than their efficiency in energy storage [24]. VAT releases high levels of adipokines that are involved in inflammation and angiogenesis, including interleukin-6, vascular endothelial growth factor, and plasminogen activator inhibitor 1 [24]. In our study, BMI was not significantly correlated with VAT, indicating that the use of BMI would not provide consistent results in assessing the association between obesity and RCC prognosis. Among anthropometric measurements, the VAT content measured via CT has recently been examined for its utility in predicting the risk of cancer.

Five studies have examined the VAT content in patients with localized and/or advanced RCC [25]. Among these, three reported that low VAT contents are associated with poor prognosis in patients with RCC [25], and one study reported no association between VAT contents and overall mortality [26]. Park and colleagues reported that the lowest and the highest vs. the second quartiles of the VAT\% are associated with a higher risk of recurrence [23]. Most studies have reported better prognosis in patients with high obesity, especially in those with localized SRMs [11, 23]. Moreover, Parker et al. reported that, in terms of aggressiveness, high BMI is associated with the presentation of a less aggressive form of RCC [9].

Among 28 studies that analyzed the body composition regarding the clinical outcomes of RCC in October 2016, 9 studies used fat index, which is the fat area divided by the height of the patients [25]. Since 19 studies 
Table 3 Expression of target genes in patients with clear-cell renal-cell carcinoma characterized by high/low visceral adiposity

\begin{tabular}{|c|c|c|c|c|}
\hline mRNA expression $(\times 100)$ & $\begin{array}{l}\text { Low visceral adiposity } \\
(N=100)\end{array}$ & $\begin{array}{l}\text { High visceral adiposity } \\
(N=100)\end{array}$ & $P^{a}$ & $P^{b}$ \\
\hline & Frozen tissue & & & \\
\hline FOXC2 & $17.011 \pm 33.556$ & $7.896 \pm 14.304$ & 0.014 & 0.003 \\
\hline CLIP4 & $17.158 \pm 32.455$ & $9.365 \pm 12.712$ & 0.027 & 0.121 \\
\hline PBRM1 & $8.950 \pm 11.257$ & $7.032 \pm 8.787$ & 0.181 & 0.249 \\
\hline SETD2 & $1.476 \pm 2.153$ & $2.077 \pm 2.316$ & 0.059 & 0.759 \\
\hline BAP1 & $18.530 \pm 59.910$ & $1.649 \pm 6.515$ & 0.006 & 0.201 \\
\hline KDM5C & $1.744 \pm 2.704$ & $1.954 \pm 5.187$ & 0.720 & 0.508 \\
\hline$A Q P 1$ & $1.283 \pm 1.486$ & $1.958 \pm 0.981$ & $<0.001$ & 0.008 \\
\hline DDX11 & $10.196 \pm 10.477$ & $1.890 \pm 2.875$ & $<0.001$ & $<0.001$ \\
\hline BAIAP2LI & $3.007 \pm 4.574$ & $2.403 \pm 3.139$ & 0.277 & 0.051 \\
\hline \multirow[t]{2}{*}{ TMEM38B } & $4.627 \pm 7.711$ & $7.055 \pm 12.656$ & 0.103 & 0.382 \\
\hline & Plasma & & & \\
\hline FOXC2 & $16.708 \pm 11.659$ & $16.235 \pm 8.215$ & 0.740 & 0.705 \\
\hline CLIP4 & $16.848 \pm 22.763$ & $17.631 \pm 22.080$ & 0.805 & 0.895 \\
\hline PBRM 1 & $2.452 \pm 2.180$ & $5.751 \pm 41.896$ & 0.417 & 0.099 \\
\hline SETD2 & $1.339 \pm 1.690$ & $2.346 \pm 1.388$ & $<0.001$ & 0.512 \\
\hline BAP1 & $98.325 \pm 357.418$ & $43.885 \pm 244.658$ & 0.210 & 0.633 \\
\hline KDM5C & $13.468 \pm 19.377$ & $6.992 \pm 9.286$ & 0.003 & 0.776 \\
\hline$A Q P 1$ & $12.095 \pm 19.380$ & $8.017 \pm 16.235$ & 0.108 & 0.286 \\
\hline DDX11 & $5.484 \pm 11.271$ & $2.641 \pm 2.657$ & 0.016 & 0.081 \\
\hline BAIAP2L 1 & $9.706 \pm 15.835$ & $4.965 \pm 11.904$ & 0.018 & 0.140 \\
\hline TMEM38B & $17.087 \pm 21.024$ & $22.035 \pm 33.570$ & 0.213 & 0.523 \\
\hline
\end{tabular}

Data are shown as the means \pm standard deviations

${ }^{a} P$ values determined using Student's t-test for univariate analysis

${ }^{\mathrm{b}} P$ values determined using logistic regression for multivariate analysis

Table 4 Predictors of high visceral adiposity in clinical T1a clear-cell renal-cell carcinoma

\begin{tabular}{|c|c|c|c|c|}
\hline & \multicolumn{2}{|l|}{ Univariate } & \multicolumn{2}{|l|}{ Multivariate } \\
\hline & OR $(95 \% \mathrm{Cl})$ & $P^{a}$ & OR $(95 \% \mathrm{Cl})$ & $P^{b}$ \\
\hline \multicolumn{5}{|l|}{ Clinical parameters } \\
\hline Gender (reference male) & $0.055(0.019-0.162)$ & $<0.001$ & $0.000(0.000-0.000)$ & 0.997 \\
\hline BMI $\left(\mathrm{kg} / \mathrm{m}^{2}\right)$ & $1.496(1.311-1.707)$ & $<0.001$ & $1.148(0.957-1.376)$ & 0.138 \\
\hline Hypercholesterolemia (vs. none) & $3.273(1.018-10.523)$ & 0.047 & $3.042 \times e^{10}$ & 0.996 \\
\hline \multicolumn{5}{|l|}{ Smoking (vs. never) } \\
\hline Former & $3.353(1.653-6.803)$ & 0.001 & $0.284(0.080-1.007)$ & 0.051 \\
\hline Current & 16.185 (6.650-39.392) & $<0.001$ & $2.406(0.606-9.545)$ & 0.212 \\
\hline \multicolumn{5}{|l|}{ Alcohol (vs. never) } \\
\hline Former & $4.747(2.055-10.964)$ & $<0.001$ & $1.854(0.383-8.965)$ & 0.443 \\
\hline Current & $3.048(1.575-5.895)$ & 0.001 & $0.374(0.109-1.290)$ & 0.119 \\
\hline \multicolumn{5}{|l|}{ mRNA expression levels } \\
\hline DDX11 (frozen tissue) & $0.785(0.726-0.850)$ & $<0.001$ & $0.816(0.706-0.943)$ & 0.006 \\
\hline $\begin{array}{l}\text { ISUP nuclear grade } \\
\text { (reference low-grade) }\end{array}$ & $0.070(0.034-0.142)$ & $<0.001$ & $0.245(0.061-0.974)$ & 0.046 \\
\hline
\end{tabular}

a $P$ values determined using logistic regression for univariate analysis

${ }^{\mathrm{b}} P$ values determined using logistic regression for multivariate analysis. $B M I$ body mass index 
Table 5 Expression of target genes in patients with clear-cell renal-cell carcinoma characterized by high/low ISUP nuclear grade

\begin{tabular}{|c|c|c|c|c|}
\hline mRNA expression $(\times 100)$ & $\begin{array}{l}\text { Low-grade } \\
(N=116)\end{array}$ & $\begin{array}{l}\text { High-grade } \\
(N=84)\end{array}$ & $P^{a}$ & $P^{b}$ \\
\hline & Frozen tissue & & & \\
\hline FOXC2 & $14.360 \pm 29.842$ & $9.820 \pm 19.779$ & 0.226 & 0.855 \\
\hline CLIP4 & $10.332 \pm 15.012$ & $17.307 \pm 33.837$ & 0.080 & 0.911 \\
\hline PBRM1 & $7.592 \pm 8.283$ & $8.543 \pm 12.242$ & 0.538 & 0.391 \\
\hline SETD2 & $2.615 \pm 2.606$ & $0.619 \pm 0.633$ & $<0.001$ & 0.095 \\
\hline BAP1 & $3.074 \pm 12.171$ & $19.778 \pm 64.299$ & 0.021 & 0.831 \\
\hline KDM5C & $1.911 \pm 4.806$ & $1.763 \pm 2.970$ & 0.803 & 0.553 \\
\hline$A Q P 1$ & $2.337 \pm 1.052$ & $0.631 \pm 0.903$ & $<0.001$ & 0.117 \\
\hline DDX11 & $1.177 \pm 2.103$ & $12.763 \pm 9.870$ & $<0.001$ & $<0.001$ \\
\hline BAIAP2L1 & $3.155 \pm 4.468$ & $2.084 \pm 2.931$ & 0.042 & 0.448 \\
\hline \multirow[t]{2}{*}{ TMEM38B } & $6.567 \pm 12.125$ & $4.838 \pm 7.751$ & 0.221 & 0.511 \\
\hline & Plasma & & & \\
\hline FOXC2 & $16.649 \pm 8.717$ & $16.226 \pm 11.721$ & 0.770 & 0.490 \\
\hline CLIP4 & $16.241 \pm 20.357$ & $18.619 \pm 24.948$ & 0.460 & 0.333 \\
\hline PBRM1 & $5.672 \pm 38.886$ & $2.065 \pm 1.880$ & 0.397 & 0.538 \\
\hline SETD2 & $2.736 \pm 1.488$ & $0.610 \pm 0.771$ & $<0.001$ & 0.269 \\
\hline BAP1 & $26.289 \pm 146.051$ & $132.993 \pm 435.106$ & 0.033 & 0.520 \\
\hline KDM5C & $6.804 \pm 8.069$ & $14.961 \pm 21.136$ & 0.001 & 0.964 \\
\hline$A Q P 1$ & $8.376 \pm 16.698$ & $12.376 \pm 19.408$ & 0.129 & 0.965 \\
\hline$D D \times 11$ & $3.545 \pm 7.810$ & $4.778 \pm 8.911$ & 0.311 & 0.953 \\
\hline BAIAPZL1 & $5.098 \pm 12.002$ & $10.425 \pm 16.291$ & 0.012 & 0.827 \\
\hline TMEM38B & $21.343 \pm 30.192$ & $17.099 \pm 24.749$ & 0.277 & 0.950 \\
\hline
\end{tabular}

Data are shown as the means \pm standard deviations

${ }^{a} P$ values determined using Student's $t$ test for univariate analysis

${ }^{\mathrm{b}} P$ values determined using logistic regression for multivariate analysis

used the fat area, we used it as well. However, there could be some bias in using only the fat area, not adjusted to the height of the patients.

Although subcutaneous adipose tissue is not associated with perioperative outcomes and survival in RCC, for other cancers, subcutaneous adipose tissue is reportedly associated with cancer-survival outcomes. Takamasa et al. reported that high subcutaneous adipose tissue volume in hepatocellular carcinoma is associated with better survival outcomes when treated with transcatheter intra-arterial therapies [27]. Moreover, leptin and adiponectin, which play a role in cancer biology, are both influenced by VAT and the subcutaneous adipose tissue $[28,29]$. Therefore, although subcutaneous adipose tissue is not significantly associated with aggressive RCC, we should not overlook the unidentified importance of the subcutaneous adipose tissue.

DDX11 expression, which is involved in cell-cycle progression, is used to predict tumor aggressiveness in clinically localized T1-stage ccRCC [16, 17]. Additionally, the inhibition of DDX11 expression decreases the proliferation rate of melanoma cells and induces apoptosis [30]. In patients with lung adenocarcinoma, upregulated $D D X 11$ expression is associated with poor prognosis [31].

Consistent with the results of previous studies, our present study showed an inverse relationship between high visceral adiposity and the expression of DDX11 mRNA in the frozen tissues. Previously, we showed that aggressive ccRCC, such as that associated with synchronous metastasis, recurrence, and/or cancerspecific death, is also associated with the upregulated expression of DDX11 mRNA in both plasma and frozen tissues. Most studies showed that high VAT contents are associated with improved prognosis; thus, we suggest that less aggressive ccRCC is likely associated with high VAT contents. The results obtained in our present study indicated that non-aggressive ccRCC is associated with high VAT contents and low expression of $D D X 11$. Based on these results, conservative therapeutic options, such as ablation and active surveillance, would be prudent strategies for treatment of patients with small ccRCC, a high VAT, and decreased DDX11 expression. 
The underlying mechanism that links visceral adiposity to the upregulation of $D D X 11$ expression is unknown. The pathogenesis of how $D D X 11$ is involved in adipogenesis and cancer progression is undetermined although some suggestions for the plausible mechanisms might be possible. DDX11, a DNA-dependent ATPase and helicase, plays an important role in the cohesion of chromosome arms and centromeres [32]. The depletion of $D D X 11$ results in mitotic failure because the replicated chromosomes fail to segregate after prometaphase [32]. DDX11 expression may be associated with the G1$S$ phase of the cell-cycle and the pathways involved in DNA replication [32]. Recent studies suggest that adipocyte differentiation, lipogenesis, and lipolysis are strongly modulated by cell-cycle regulators, which control the checkpoints for cell duplication [33]. Our results suggest that $D D X 11$, which is involved in cell-cycle regulation, may be associated with VAT generation. Because the exact pathways connecting cell-cycle regulation and adiposity remain unknown, future studies should elucidate the mechanisms underlying visceral adiposity and $D D X 11$ expression. We are under in vitro experiments on how DDX11 affects both adipogenesis and cancer progression. This study suggested the possible mechanisms linking VAT, $D D X 11$, and tumor aggressiveness and provided support for future studies including in vitro experiments we are undergoing.

Although FOXC2 and AQP1 were not significantly associated with ISUP nuclear grades, they were significantly associated with VAT. FOXC2 and AQP1 were the first to be identified as the significant genes associated with ccRCC aggressiveness such as synchronous metastasis and ccRCC-specific death in on our previous studies [16, 17, 34]. Our group was the first to identify FOXC2 as a biomarker of aggressive ccRCC [16, 34]. One study reported upregulation of $F O X C 2$ in aggressive ccRCC [34], while downregulation of FOXC2 in aggressive ccRCC was observed in the subsequent study [16]. We believe that these differences might have resulted from different definition of aggressiveness. Ahn et al. analyzed the biomarkers that are associated with synchronous metastasis [34], while Park et al. demonstrated the biomarkers associated with a tumor exhibiting synchronous metastasis, recurrence, or cancer-specific death, and synchronous metastasis [16]. According to other studies, the results are controversial as well, with one study reporting upregulation of FOXC2 in association with cancer metastasis and epithelial-mesenchymal transition $[35,36]$, while other study reports $F O X C 2$ upregulation acts as a checkpoint to inhibit epithelial cell dedifferentiation [37]. Although several studies have reported the usefulness of urine AQP1, few studies reported analysis of the frozen tissue AQP1 in RCC. Huang et al. demonstrated that frozen tissue $A Q P 1$ expression was significantly differed according to RCC subtype-specific expression, and its expression level provided prognostic information for ccRCC patients [38].

Our study was the first to evaluate the association between visceral adiposity and mRNA expression of target genes. Moreover, our results enabled us to easily infer the aggressiveness of ccRCCs using visceral adiposity calculated from preoperative CT without any invasive diagnostic modalities. Although mutations in each of these kidney cancer genes result in dysregulation of metabolic pathways, suggesting that kidney cancer is a disease of cell metabolism [39], no studies have attempted to find the association of gene expression or tumor aggressiveness of ccRCC with metabolic factors such as adiposity. We believe that this study could be the cornerstone for the ccRCC metabolism in association with biomarker expression and tumor aggressiveness.

Our study has a few limitations. First, the ITH of primary tumors is a considerable problem, even in SRMs [25]. ITH causes sampling bias in conventional needle biopsies. Clinical trials are currently examining the use of circulating tumor DNA in plasma to overcome the limitations imposed by ITH. Second, we could not use visceral adiposity and target-gene expression to predict prognostic indexes, such as cancer-specific or progression-free survival, in patients with ccRCC, owing to the short follow-up period. Only one patient developed recurrence among the 200 patients included in this study, and no other patients developed recurrence, metastasis, or cancer-specific death. WHO/ISUP grading system has several advantages over the former Fuhrman grading system, that are easier to apply, more reproducible and clinically relevant with its relevance for prognosis and serving as an alternative means of categorizing tumors for future patient management [19, 40]. Since high nuclear grade is currently the most important and significant prognostic factor for predicting oncological outcomes [41], we evaluated the association between the expression of biomarkers and a high nuclear grade. Third, the study population was relatively small. Future studies should investigate the correlations among visceral adiposity, target-gene expression, and prognosis in large populations of patients with ccRCC.

\section{Conclusions}

In the present study, we investigated the association between visceral adiposity and target-gene mRNA expression in patients with localized small ccRCC. DDX11 mRNA levels in the frozen tissues and plasma are significantly associated with high visceral adiposity. Quantifying the VAT contents in preoperative CT scans will enable us to infer the aggressiveness of small ccRCCs in clinical practice. The role of DDX11 in the regulation of VAT warrants further investigation in future studies. 


\section{Abbreviations}

Cl: Confidence intervals; CT: Computed tomography; HU: Hounsfield unit; ISUP: International Society of Urologic Pathologists; ITH: Intratumoral heterogeneity; KHIDI: Korea Health Industry Development Institute; OR: Odds ratios; RCC: Renal-cell carcinoma; SAT: Subcutaneous adipose tissue; SRM: Small renal masses; TAT: Total adipose tissue; VAT: Visceral adipose tissue; WHO: World Health Organization

\section{Supplementary Information}

The online version contains supplementary material available at https://doi. org/10.1186/s40170-021-00251-y.

\section{Additional file 1: Table S1}

\section{Acknowledgements}

None.

\section{Authors' contributions}

JSP: literature search, figure preparation, study design, data collection, data analysis, data interpretation, and writing; WSJ: data collection; JK: data collection; SHL: data collection; KHR: data collection; WSH: study design, data collection, data analysis, data interpretation, and writing. All authors read and approved the final manuscript.

\section{Funding}

This study was supported by a grant from the Korea Health Technology R\&D Project through the Korea Health Industry Development Institute funded by the Ministry of Health \& Welfare, Republic of Korea (grant number: HI17C1095).

\section{Availability of data and materials}

Data are not publically available to other researchers and only be permitted after the approval of IRB.

\section{Declarations}

Ethics approval and consent to participate

All subjects gave their informed consent for inclusion before they participated in the study. The study was conducted in accordance with the Declaration of Helsinki, and the protocol was approved by the Ethics Committee of the Yonsei University Health System (project no: 4-2018-0753).

\section{Consent for publication}

All authors agree for publication.

\section{Competing interests}

The authors declare that they have no competing interests.

Received: 16 July 2020 Accepted: 15 March 2021

Published online: 06 April 2021

\section{References}

1. Siegel RL, Miller KD, Jemal A. Cancer statistics, 2018. CA Cancer J Clin. 2018; 68:7-30

2. Wolf MM, Kimryn Rathmell W, Beckermann KE. Modeling clear cell renal cell carcinoma and therapeutic implications. Oncogene. 2020;39:3413-26.

3. Capitanio U, Montorsi F. Renal cancer. Lancet. 2016;387:894-906.

4. Manley BJ, Reznik E, Ghanaat M, Kashan M, Becerra MF, Casuscelli J, et al. Characterizing recurrent and lethal small renal masses in clear cell renal cell carcinoma using recurrent somatic mutations. Urol Oncol. 2019;37:12-7.

5. Calle EE, Rodriguez C, Walker-Thurmond K, Thun MJ. Overweight, obesity, and mortality from cancer in a prospectively studied cohort of U.S. adults. N Engl J ed. 2003;348:1625-38.

6. Chow W-H, Dong LM, Devesa SS. Epidemiology and risk factors for kidney cancer. Nat Rev Urol. 2010;7:245-57.

7. Kamat AM, Shock RP, Naya Y, Rosser CJ, Slaton JW, Pisters LL. Prognostic value of body mass index in patients undergoing nephrectomy for localized renal tumors. Urology. 2004;63:46-50.
8. Schips L, Lipsky K, Zigeuner R, Gidaro S, Salfellner M, Rehak P, et al. Does overweight impact on the prognosis of patients with renal cell carcinoma? A single center experience of 683 patients. J Surg Oncol. 2004;88:57-61.

9. Parker AS, Lohse CM, Cheville JC, Thiel DD, Leibovich BC, Blute ML. Greater body mass index is associated with better pathologic features and improved outcome among patients treated surgically for clear cell renal cell carcinoma. Urology. 2006;68:741-6.

10. Awakura Y, Nakamura E, Ito N, Yamasaki T, Kamba T, Kamoto T, et al. Influence of body mass index on prognosis of Japanese patients with renal cell carcinoma. Urology. 2007;70:50-4.

11. Jeon HG, Jeong IG, Lee JH, Lee CJ, Kwak C, Kim HH, et al. Prognostic value of body mass index in Korean patients with renal cell carcinoma. J Urol. 2010;183:448-54.

12. Haferkamp A, Pritsch M, Bedke J, Wagener N, Pfitzenmaier J, Buse S, et al. The influence of body mass index on the long-term survival of patients with renal cell carcinoma after tumour nephrectomy. BJU Int. 2008;101: 1243-6.

13. Donat SM, Salzhauer EW, Mitra N, Yanke BV, Snyder ME, Russo P. Impact of body mass index on survival of patients with surgically treated renal cell carcinoma. J Urol. 2006;175:46-52.

14. Ather MH, Nazim SM. Impact of Charlson's comorbidity index on overall survival following tumor nephrectomy for renal cell carcinoma. Int Urol Nephrol. 2010;42:299-303.

15. Doyle SL, Donohoe CL, Lysaght J, Reynolds JV. Visceral obesity, metabolic syndrome, insulin resistance, and cancer. Proc Nutr Soc. 2012;71:181-9.

16. Park JS, Lee HJ, Cho NH, Kim J, Jang WS, Heo JE, et al. Risk prediction tool for aggressive tumors in clinical T1 stage clear cell renal cell carcinoma using molecular biomarkers. Comput Struct Biotechnol . 2019;17:371-7.

17. Park JS, Pierorazio PM, Lee JH, Lee HJ, Lim YS, Jang WS, et al. Gene expression analysis of aggressive clinical T1 stage clear cell renal cell carcinoma for identifying potential diagnostic and prognostic biomarkers. Cancers. 2020;12:222.

18. Moch H, Humphrey PA, Ulbright TM, Reuter VE. WHO classification of tumours of the urinary system and male genital organs. Lyon: International Agency for Research on Cancer (IARC) Press; 2016.

19. Delahunt B, Cheville JC, Martignoni G, Humphrey PA, Magi-Galluzzi C, McKenney J, et al. The International Society of Urological Pathology (ISUP) grading system for renal cell carcinoma and other prognostic parameters. Am J Surg Pathol. 2013;37:1490-504.

20. Zhu Y, Wang H-K, Zhang H-L, Yao X-D, Zhang S-L, Dai B, et al. Visceral obesity and risk of high grade disease in clinical t1a renal cell carcinoma. J Urol. 2013;189:447-53.

21. WHO expert consultation. Appropriate body-mass index for Asian populations and its implications for policy and intervention strategies. Lancet. 2004;363:157-63.

22. Bergström A, Hsieh C-C, Lindblad P, Lu C-M, Cook NR, Wolk A. Obesity and renal-cell cancer-a quantitative review. Br J Cancer. 2001;85:984-90.

23. Park YH, Lee JK, Kim KM, Kook HR, Lee H, Kim KB, et al. Visceral obesity in predicting oncologic outcomes of localized renal cell carcinoma. J Urol. 2014;192:1043-9.

24. Ibrahim MM. Subcutaneous and vaisceral adipose tissue: structural and functional differences. Obes Rev. 2010;11:11-8.

25. Vrieling A, Kampman E, Knijnenburg NC, Mulders PF, Sedelaar JPM, Baracos VE, et al. Body composition in relation to clinical outcomes in renal-cell cancer: a systematic review and meta-analysis. Eur Urol Focus. 2018;4:420-34.

26. Mano R, Hakimi AA, Zabor EC, Bury MA, Donati OF, Karlo CA, et al. Association between visceral and subcutaneous adiposity and clinicopathological outcomes in non-metastatic clear cell renal cell carcinoma. Can Urol Assoc J. 2014;8:E675-80.

27. Fujiwara N, Nakagawa H, Kudo $Y$, Tateishi R, Taguri M, Watadani T, et al. Sarcopenia, intramuscular fat deposition, and visceral adiposity independently predict the outcomes of hepatocellular carcinoma. J Hepatol. 2015;63:131-40.

28. Zhang Q, Sun L-J, Yang Z-G, Zhang G-M, Huo R-C. Influence of adipocytokines in periprostatic adipose tissue on prostate cancer aggressiveness. Cytokine. 2016;85:148-56.

29. Park K-G, Park KS, Kim M-J, Kim H-S, Suh Y-S, Ahn JD, et al. Relationship between serum adiponectin and leptin concentrations and body fat distribution. Diabetes Res Clin Pract. 2004:63:135-42. 
30. Bhattacharya C, Wang X, Becker D. The DEAD/DEAH box helicase, DDX11, is essential for the survival of advanced melanomas. Mol Cancer. 2012;11:82.

31. Li J, Liu L, Liu X, Xu P, Hu Q, Yu Y. The role of upregulated DDX11 as a potential prognostic and diagnostic biomarker in lung adenocarcinoma. J Cancer. 2019;10:4208-16.

32. Lopez-Mejia IC, Castillo-Armengol J, Lagarrigue S, Fajas L. Role of cell cycle regulators in adipose tissue and whole body energy homeostasis. Cell Mol Life Sci. 2018;75:975-87.

33. von Haehling S, Morley JE, Coats AJS, Anker SD. Ethical guidelines for publishing in the Journal of Cachexia, Sarcopenia and Muscle: update 2017. J Cachexia Sarcopenia Muscle. 2017;8:1081-3.

34. Ahn J, Han KS, Heo JH, Bang D, Kang YH, Jin HA, et al. FOXC2 and CLIP4: a potential biomarker for synchronous metastasis of $\leq 7-\mathrm{cm}$ clear cell renal cell carcinomas. Oncotarget. 2016;7:51423-34.

35. Mani SA, Yang J, Brooks M, Schwaninger G, Zhou A, Miura N, et al. Mesenchyme Forkhead 1 (FOXC2) plays a key role in metastasis and is associated with aggressive basal-like breast cancers. Proc Natl Acad Sci U S A. 2007;104:10069-74

36. Bard JB, Lam MS, Aitken S. A bioinformatics approach for identifying candidate transcriptional regulators of mesenchyme-to-epithelium transitions in mouse embryos. Dev Dyn. 2008;237:2748-54.

37. Hader C, Marlier A, Cantley L. Mesenchymal-epithelial response to injury: the role of Foxc2. Oncogene. 2010;29:1031-40

38. Huang Y, Murakami T, Sano F, Kondo K, Nakaigawa N, Kishida T, et al. Expression of aquaporin 1 in primary renal tumors: a prognostic indicator for clear-cell renal cell carcinoma. Eur Urol. 2009:56:690-8.

39. Linehan WM, Srinivasan R, Schmidt LS. The genetic basis of kidney cancer: a metabolic disease. Nat Rev Urol. 2010;7:277-85.

40. Warren AY, Harrison D. WHO/ISUP classification, grading and pathological staging of renal cell carcinoma: standards and controversies. World J Urol. 2018;36:1913-26.

41. Suzuki K, Mizuno R, Mikami S, Tanaka N, Kanao K, Kikuchi E, et al. Prognostic significance of high nuclear grade in patients with pathologic T1a renal cell carcinoma. Jpn J Clin Oncol. 2012;42:831-5.

\section{Publisher's Note}

Springer Nature remains neutral with regard to jurisdictional claims in published maps and institutional affiliations.

Ready to submit your research? Choose BMC and benefit from:

- fast, convenient online submission

- thorough peer review by experienced researchers in your field

- rapid publication on acceptance

- support for research data, including large and complex data types

- gold Open Access which fosters wider collaboration and increased citations

- maximum visibility for your research: over $100 \mathrm{M}$ website views per year

At $\mathrm{BMC}$, research is always in progress.

Learn more biomedcentral.com/submissions 